\title{
Expression levels of MRP1, GST- $\pi$, and GSK3 $\beta$ in ovarian cancer and the relationship with drug resistance and prognosis of patients
}

\author{
XIAOJING TONG, JIAO ZHAO, YUHUA ZHANG, PENG MU and XIAOBIN WANG \\ Department of Gynecology, Liaoning Cancer Hospital and Institute, \\ Cancer Hospital of China Medical University, Shenyang, Liaoning 110042, P.R. China
}

Received January 15, 2019; Accepted April 22, 2019

DOI: $10.3892 / 01.2019 .10315$

\begin{abstract}
Expression levels of multidrug resistance-associated protein $1(M R P 1)$, glutathione S-transferase $\pi(G S T-\pi)$ and glycogen synthase kinase-3 $\beta(G S K 3 \beta)$ were investigated in ovarian epithelial cancer and the relationship with the primary drug resistance of patients with ovarian cancer to chemotherapy. One hundred and twenty-one ovarian cancer tissue samples from patients who underwent ovarian cancer resection from January 2013 to June 2015 in Liaoning Cancer Hospital and Institute, Cancer Hospital of China Medical University were enrolled in the Experimental group, while 58 ovarian tissue samples from patients with fallopian tube obstruction but with no ovarian cancer who received surgical treatment for blocked fallopian tube were included in the Control group. After the detection of the expression levels of MRP1, GST- $\pi$, and GSK $3 \beta$ mRNA by RT-PCR and the analysis of related clinical pathological factors, patients in the Experimental group were divided into the Chemotherapy-sensitive and Chemotherapy-resistant groups according to the chemotherapy efficacy. Additionally, with the mean expression levels of $M R P 1, G S T-\pi$, and $G S K 3 \beta$ in ovarian cancer tissues as the boundaries, the expression levels of the three genes in the Experimental group were classified into high expression and low expression. Ovarian cancer tissues had much higher expression levels of MRP1, GST- $\pi$, and GSK $3 \beta$ mRNA than normal ovarian tissues $(\mathrm{P}<0.05)$. The expression levels of MRP1, GST- $\pi$, and GSK3 $\beta$ mRNA in the Chemotherapy-sensitive group were significantly lower than those in the Chemotherapy-resistant group $(\mathrm{P}<0.05)$. Patients with high expression of $M R P 1, G S T-\pi$, and $G S K 3 \beta$ mRNA
\end{abstract}

Correspondence to: Dr Xiaobin Wang, Department of Gynecology, Liaoning Cancer Hospital and Institute, Cancer Hospital of China Medical University, 44 Xiaoheyan Road, Dadong, Shenyang, Liaoning 110042, P.R. China

E-mail: sw38v5@163.com; 18900917336@163.com

Key words: multidrug resistance-associated protein 1, GST- $\pi$, GSK $3 \beta$, ovarian cancer, clinical pathology, chemotherapy-resistance, prognosis had a much lower 3-year survival rate than patients with low expression of the genes $(\mathrm{P}<0.05)$. Highly expressed in patients with ovarian cancer, $M R P 1, G S T-\pi$, and $G S K 3 \beta$ mRNA play an important role in the development and drug resistance of ovarian cancer, which ensures this study is of positive clinical guiding significance in developing proper treatment for ovarian cancer and evaluating the efficacy of chemotherapy.

\section{Introduction}

Ovarian cancer, a common gynecological malignant tumor, is one of the major malignant tumors causing female death (1). At present, the treatment of ovarian cancer mainly adopts methods of surgery and chemotherapy, among which intravenous chemotherapy can not only promote the atrophy of tumor lesions, but also significantly reduce the tumor recurrence rate and metastasis rate $(2,3)$. However, some studies have found that intravenous chemotherapy for ovarian cancer can arouse a subsequent drug resistance of many patients, and that longterm chemotherapy and previous history of chemotherapy can also promote the development of drug resistance (4). At present, drugs used for the clinical chemotherapy for ovarian cancer are mainly paclitaxel and platinum drugs. However, patients receiving the same chemotherapy regimen can be affected with different efficacy and different risk due to the differences in the individual constitution and the sensitivity to chemotherapy, which is why the exploration of a molecular mechanism that can predict chemotherapy resistance is imperative (5).

Studies have shown that multidrug resistance-associated protein 1 (MRP1), glutathione S-transferase $\pi(\mathrm{GST}-\pi)$, and glycogen synthase kinase- $3 \beta$ (GSK3 $\beta$ ) may be associated with chemotherapy resistance and prognosis of ovarian cancer (6-8). As a transmembrane protein-encoding gene, MRP1 is able to cause drug resistance mainly by reducing the intracellular concentration of drugs (9). GST- $\pi$, is a detoxification enzyme, and its contribution to drug resistance is generally achieved by removing toxic substance from tumor cells to weaken the killing effect on cells (10). GSK-3 $\beta$ is a key target gene downstream of the Akt signaling pathway, an important component of various signal transduction pathways in cells, and is involved in biological functions such as 
intracellular glucose metabolism and cell proliferation and differentiation (11). It has been previously shown that GSK-3 $\beta$, when its ser9 residue is inactivated by phosphorylation, has an inhibitory effect on apoptosis of ovarian cancer cells induced by cisplatin (12).

Owing to the complicated mechanism of drug resistance in tumor cells that probably involves multiple drug-resistance related genes, and the still few clinical studies on the prognosis and resistance to ovarian cancer concerning $M R P 1, G S T-\pi$, $P-G S K 3 \beta$, this study investigated the expression of $M R P 1$, $G S T-\pi$, and $P-G S K 3 \beta$ in ovarian cancer patients with different chemotherapy outcomes and their relationship with the prognosis to providing more theoretical data for the prediction of chemotherapy resistance in ovarian cancer.

\section{Patients and methods}

General information. One hundred and twenty-one ovarian cancer tissue samples from patients (with an average age of $51.23 \pm 11.31$ years) who underwent ovarian cancer resection from January 2013 to June 2015 in the Liaoning Cancer Hospital and Institute, Cancer Hospital of China Medical University (Shenyang, China) were retrospectively analyzed, including 31 cases of mucinous cystadenocarcinoma, 57 cases of serous cystadenocarcinoma, 23 cases of endometrial carcinoma, and 10 cases of clear cell carcinoma. There were 71 patients at stage I-II, 50 patients at stage III-IV on the basis of different clinical pathological stages and 52 cases of high differentiation, 41 cases of moderate differentiation, and 28 cases of poor differentiation according to the classification of histological grading. In total, 121 patients from whom ovarian cancer tissue samples were obtained (Experimental group) received chemotherapy after the ovarian cancer resection, while 58 subjects with fallopian tube obstruction but with no ovarian cancer all received surgical treatment for blocked fallopian tube before providing ovarian tissue samples for the Control group. No significant difference was proven between the two groups in terms of age and number of births $(\mathrm{P}>0.05)$. The general information of patients is shown in Table I.

Inclusion criteria were: patients confirmed to have ovarian cancer by pathological diagnosis. Exclusion criteria were: patients who received chemoradiotherapy before surgery; patients with severe liver and kidney dysfunction; ovarian cancer patients complicated with other tumors; patients with communication impairment or cognitive dysfunction; patients who did not cooperate with the experiment.

All the patients and their families signed the informed consent form of this experiment. The study was approved by the Ethics Committee of Liaoning Cancer Hospital and Institute, Cancer Hospital of China Medical University.

Experimental reagents and drugs. Paclitaxel was purchased from Yunnan Hande Biotechnology Co., Ltd., Yunnan, China (license number of medical products permitted by SFDA: H109603221); cisplatin was purchased from Qilu Pharmaceutical Co., Ltd. Jinan, China (license number of medical products permitted by SFDA: H37021358). TRIzol reagent and cDNA reverse transcription kit used in this experiment were from Applied Biosystems-Invitrogen; Thermo Fisher Scientific, Inc., Waltham, MA, USA. RT-PCR kit was purchased from CWBio, Beijing, China. The primers were produced and designed by Sangon Biotech (Shanghai) Co. Ltd., Shanghai, China. Dexamethasone was purchased from Xi'an Reyphon Pharmaceutical Co., Ltd., Xi'an, China (license number of medical products permitted by SFDA: H20053754). Diphenhydramine was manufactured by Tonghua Mintai Pharmaceutical Co., Ltd., Tonghua, China (license number of medical products permitted by SFDA: H22025212).

Chemotherapy regimen. Dexamethasone $(20 \mathrm{mg})$ was taken orally $12 \mathrm{~h}$ before the chemotherapy treatment, and diphenhydramine was taken $30 \mathrm{~min}$ before the chemotherapy treatment. The chemotherapy in this experiment used paclitaxel plus cisplatin: paclitaxel was infused at a concentration of $135 \mathrm{mg} / \mathrm{m}^{2}$, and then an infusion of cisplatin at a concentration of $75 \mathrm{mg} / \mathrm{m}^{2}$ was begun from the third day of chemotherapy. The chemotherapy was for 6 courses of treatment and each course equalled 3 weeks.

RT-PCR detection of MRPI $m R N A, G S T-\pi m R N A$, and GSK3 $\beta$ mRNA expression levels. The cut and ground, ovarian cancer tissues and normal ovarian tissues were mixed with TRIzol reagent for the extraction of RNA, the purity and concentration of which were then detected by UV spectrophotometer. Next, $1 \mu \mathrm{g}$ of total RNA from each sample was taken for reverse transcription of cDNA according to the kit instructions. The reaction parameters were: $37^{\circ} \mathrm{C}$ for $10 \mathrm{~min}$, $42^{\circ} \mathrm{C}$ for $45 \mathrm{~min}$, and $70^{\circ} \mathrm{C}$ for $5 \mathrm{~min}$. Then TaqMan PCR (Beyotime, Shanghai, China) amplification of cDNA followed with MRP1 and GSK3 using GAPDH as internal reference and GST- $\pi$ using $\beta$-actin as internal reference. Primer sequences are shown in Table II. PCR reaction conditions of MRP1: pre-denaturation at $94^{\circ} \mathrm{C}$ for $2 \mathrm{~min}$, then 35 cycles of $94^{\circ} \mathrm{C}$ for $45 \mathrm{sec}$ and $55^{\circ} \mathrm{C}$ for $60 \mathrm{sec}$, followed by a final extension at $65^{\circ} \mathrm{C}$ for $20 \mathrm{sec}$; PCR reaction conditions for GST- $\pi$ mRNA: pre-denaturation at $94^{\circ} \mathrm{C}$ for $5 \mathrm{~min}$, then 35 cycles of $94^{\circ} \mathrm{C}$ for $45 \mathrm{sec}$ and annealing at $55^{\circ} \mathrm{C}$ for $35 \mathrm{sec}$, followed by a final extension at $72^{\circ} \mathrm{C}$ for $60 \mathrm{sec}$; PCR reaction conditions of GSK3 $\beta$ : pre-denaturation at $94^{\circ} \mathrm{C}$ for $3 \mathrm{~min}$, then 40 cycles of $94^{\circ} \mathrm{C}$ for $45 \mathrm{sec}$ and annealing at $60^{\circ} \mathrm{C}$ for $40 \mathrm{sec}$, with a final extension at $72^{\circ} \mathrm{C}$ for $30 \mathrm{sec}$. The relative expression of the gene was expressed by $2^{-\Delta \Delta \mathrm{Cq}}(13)$, and the RT-qPCR detection was repeated 3 times.

Observation indicators. i) A comparison was made of the MRP1, GST- $\pi$, and GSK3 $\beta$ mRNA expression levels in ovarian cancer tissues and normal ovarian tissues. ii) The efficacy of chemotherapy in patients with ovarian cancer was evaluated, and patients were classified into four types according to the classification system for recurrent ovarian cancer of the American Gynecological Oncology group (14): chemotherapy-sensitive type (patients sensitive to platinumbased chemotherapy who reached a clinical remission period after chemotherapy, but ovarian cancer recurred 6 months after the end of chemotherapy), chemotherapy-resistant type (patients with a certain response to platinum-based chemotherapy and suffering tumor recurrence within 6 months after chemotherapy stopped), inveterate cancer type (patients with very limited response to platinum-based 
Table I. General information [n (\%)].

\begin{tabular}{|c|c|c|c|c|}
\hline Factors & Experimental group $(n=121)$ & Control group $(n=58)$ & $\mathrm{t} / \chi^{2}$ value & P-value \\
\hline Age (years) & & & 4.630 & 0.099 \\
\hline$\leq 51$ & $64(52.89)$ & $32(55.17)$ & & \\
\hline$>51$ & $57(47.11)$ & $26(44.83)$ & & \\
\hline BMI $\left(\mathrm{kg} / \mathrm{m}^{2}\right)$ & & & 0.225 & 0.894 \\
\hline$\leq 21$ & $58(47.93)$ & $27(46.55)$ & & \\
\hline$>21$ & $63(52.07)$ & $31(53.45)$ & & \\
\hline Marital status & & & 0.915 & 0.633 \\
\hline Married & $109(90.08)$ & $51(87.93)$ & & \\
\hline Unmarried & $12(9.92)$ & $7(12.07)$ & & \\
\hline Childbearing history & & & 0.368 & 0.832 \\
\hline Yes & $97(80.17)$ & $47(81.03)$ & & \\
\hline No & $24(19.83)$ & $11(18.97)$ & & \\
\hline Pathology type & & & - & - \\
\hline Mucinous cystadenocarcinoma & $31(25.62)$ & - & & \\
\hline Serous cystadenocarcinoma & $57(47.11)$ & - & & \\
\hline Endometrial carcinoma & $23(19.01)$ & - & & \\
\hline Clear cell carcinoma & $10(8.26)$ & - & & \\
\hline Pathological stage & & & - & - \\
\hline I-II & $71(58.68)$ & - & & \\
\hline III-IV & $50(41.32)$ & - & & \\
\hline Degree of differentiation & & & - & - \\
\hline High & $52(42.98)$ & - & & \\
\hline Moderate & $41(33.88)$ & - & & \\
\hline Poor & $28(23.14)$ & - & & \\
\hline
\end{tabular}

Table II. Related primer sequences.

\begin{tabular}{lll}
\hline Gene name & \multicolumn{1}{c}{ Forward primers } & \multicolumn{1}{c}{ Reverse primers } \\
\hline MRP1 mRNA & 5'-AACCTGGACCCATTCAGCC-3' & 5'-GACTGGATGAGGTCGTCCGT-3' \\
GSK3 $\beta$ mRNA & 5'-ATGCCACAGCAGCGTCAG-3' & 5'-GGTCTGTCCACGGTCTCC-3' \\
GAPDH & 5'-GCCACATCGCTCAGACACC-3' & 5'-GATGGCAACAATATCCACTTTACC-3' \\
GS $\pi$ - $m R N A$ & 5'-AATGGATCCTCCACCATGCCG & 5'-GACCTCGAGCTACTGTTTCCC \\
$\beta$-actin & CCCTACACCGTGGT-3' & GTTGCCAT-3' \\
\hline
\end{tabular}

chemotherapy and thus with residual lesions), and refractory cancer type (patients unresponsive to platinum-based chemotherapy). Chemotherapy-sensitive patients were classified into the Chemotherapy-sensitive group, and patients of chemotherapy-resistant, inveterate cancer, and refractory cancer types were included in the Chemotherapy-resistant group. iii) An analysis was made of the comparison for the expression levels of MRP1 mRNA, GST- $\pi$ mRNA, and GSK3 $\beta$ mRNA between Chemotherapy-sensitive and Chemotherapy-resistant groups. iv) The relationship between the expression levels of MRP1 mRNA, GST- $\pi$ mRNA, and GSK $3 \beta$ mRNA and the clinical pathological features of ovarian cancer patients was explored. v) A follow-up for patients was performed to record the 3-year survival rate and a comparison was made between the two groups.

Statistical analysis. In this study, statistical analysis of the data was prepared by SPSS20.0 software [Bizinsight (Beijing) Information Technology Co., Ltd., Beijing, China], and all the graphs in this experiment were drawn using GraphPad Prism 6 software. Comparison of countable data was conducted with the Chi-square test, measurement data were expressed as mean \pm standard deviation. The comparison between the two groups was made using the t-test, the comparison among multiple groups was analyzed by ANOVA and LSD post hoc test, and Kaplan-Meier and log rank test were used for the 
Table III. Expression of all indexes in Chemotherapy-sensitive group and Chemotherapy-resistant group.

\begin{tabular}{lcrr}
\hline Gene name & $\begin{array}{c}\text { Chemotherapy-sensitive } \\
\text { group }(\mathrm{n}=71)\end{array}$ & $\begin{array}{c}\text { Chemotherapy-resistant } \\
\text { group (n=50) }\end{array}$ & t value \\
\hline MRP1 mRNA & $1.51 \pm 0.21$ & $2.71 \pm 0.17$ & 33.41 \\
GST- $\pi$ mRNA & $1.62 \pm 0.19$ & $2.66 \pm 0.18$ & 30.29 \\
GSK3 $\beta$ mRNA & $1.54 \pm 0.23$ & $2.59 \pm 0.17$ & 27.42 \\
\hline
\end{tabular}

Table IV. Relationship between MRP1 mRNA and different clinicopathological features in ovarian cancer.

\begin{tabular}{|c|c|c|c|c|c|c|c|c|c|c|}
\hline $\begin{array}{l}\text { Clinico- } \\
\text { pathological factor }\end{array}$ & $\mathrm{n}$ & $\begin{array}{l}\text { MRP1 } \\
\text { mRNA }\end{array}$ & $\mathrm{t} / \mathrm{F}$ value & P-value & $\begin{array}{l}\text { GST- } \pi \\
\text { mRNA }\end{array}$ & $\mathrm{t} / \mathrm{F}$ value & P-value & $\begin{array}{l}\text { GSK3 } \beta \\
\text { mRNA }\end{array}$ & $\mathrm{t} / \mathrm{F}$ value & P-value \\
\hline Age (years) & & & 1.278 & 0.204 & & 0.815 & 0.417 & & 1.498 & 0.137 \\
\hline$\leq 51$ & 64 & $2.24 \pm 0.21$ & & & $2.35 \pm 0.13$ & & & $2.10 \pm 0.16$ & & \\
\hline$>51$ & 57 & $2.19 \pm 0.22$ & & & $2.33 \pm 0.14$ & & & $2.06 \pm 0.13$ & & \\
\hline Pathological type & & & 1.209 & 0.310 & & 327.5 & $<0.050$ & & 1.522 & 0.198 \\
\hline Mucinous cystadenocarcinoma & 31 & $2.41 \pm 0.22$ & & & $2.36 \pm 0.27$ & & & $2.17 \pm 0.18$ & & \\
\hline Serous cystadenocarcinoma & 57 & $2.32 \pm 0.23$ & & & $3.27 \pm 0.28$ & & & $2.09 \pm 0.17$ & & \\
\hline Endometrial carcinoma & 23 & $2.33 \pm 0.18$ & & & $1.69 \pm 0.15$ & & & $2.10 \pm 0.19$ & & \\
\hline Clear cell carcinoma & 10 & $2.35 \pm 0.21$ & & & $1.42 \pm 0.11$ & & & $2.08 \pm 0.15$ & & \\
\hline Pathological stage & & & 23.72 & $<0.050$ & & 45.70 & $<0.050$ & & 39.01 & $<0.050$ \\
\hline I-II & 71 & $1.68 \pm 0.25$ & & & $2.01 \pm 0.11$ & & & $1.92 \pm 0.14$ & & \\
\hline III-IV & 50 & $2.89 \pm 0.31$ & & & $3.09 \pm 0.15$ & & & $3.09 \pm 0.19$ & & \\
\hline Degree of differentiation & & & 790.8 & $<0.050$ & & 1070 & $<0.050$ & & 1084 & $<0.050$ \\
\hline High & 52 & $1.25 \pm 0.21$ & & & $1.27 \pm 0.22$ & & & $1.24 \pm 0.19$ & & \\
\hline Moderate & 41 & $2.34 \pm 0.25$ & & & $2.21 \pm 0.17$ & & & $2.59 \pm 0.21$ & & \\
\hline Poor & 28 & $3.26 \pm 0.19$ & & & $3.46 \pm 0.21$ & & & $3.27 \pm 0.20$ & & \\
\hline
\end{tabular}

MRP1, multidrug resistance-associated protein 1; GST- $\pi$, glutathione S-transferase $\pi$; GSK3 $\beta$, glycogen synthase kinase-3 $\beta$.

survival analysis. $\mathrm{P}<0.05$ was considered to indicate a statistically significant difference.

\section{Results}

Expression of MRP1 mRNA, GST- $\pi$ mRNA, and GSK3 $\beta$ $m R N A$ in ovarian cancer and normal ovarian tissues. The expression levels of MRP1 mRNA, GST- $\pi$ mRNA, and GSK3 $\beta$ mRNA in ovarian cancer tissues of the Experimental group were $2.23 \pm 0.23,2.34 \pm 0.12$ and $2.07 \pm 0.17$, respectively, significantly higher than those in normal ovarian tissues of the Control group which had an expression of MRP1 mRNA at $1.01 \pm 0.12$, GST $-\pi$ mRNA at $0.94 \pm 0.14$, and GSK3 $\beta$ mRNA at $0.89 \pm 0.11$, with a statistical difference between the two groups $(\mathrm{P}<0.05)$ (Fig. 1). According to the average expression of MRP1 mRNA, GST $-\pi$ mRNA, and GSK $3 \beta$ mRNA in ovarian cancer tissues, the expression levels of the three mRNAs were divided into high expression and low expression.

Expression of MRP1 mRNA, GST- $\pi$ mRNA, and GSK3 $\beta$ $m R N A$ in Chemotherapy-sensitive group and Chemotherapyresistant group. According to the evaluation of chemotherapy efficacy for the Experimental group, 71 patients were chemotherapy-sensitive and 50 were chemotherapy-resistant. The expression levels of MRP1 mRNA, GST- $\pi$ mRNA, and GSK $3 \beta$ mRNA in the Chemotherapy-sensitive group were statistically lower than those in the Chemotherapy-resistant group $(\mathrm{P}<0.05)$ (Table III).

Relationship between MRPI mRNA, GST- $\pi$ mRNA, and GSK3 $\beta$ mRNA in ovarian cancer tissues and different clinical pathological features. The expression of MRP1 mRNA was associated with pathological stage and pathological differentiation $(\mathrm{P}<0.05)$, having no significant relationship with age and pathological type $(\mathrm{P}>0.05)$. GST- $\pi$ mRNA expression was linked to pathological type, pathological stage, and degree of differentiation $(\mathrm{P}<0.05)$, but not significantly related to age $(\mathrm{P}>0.05)$. GSK3 $\beta$ mRNA expression was associated with pathological stage and pathological differentiation $(\mathrm{P}<0.05)$, with no obvious connection with age and pathological type $(\mathrm{P}>0.05)$ (Table IV).

Relationship between MRPI mRNA, GST- $\pi$ mRNA, and GSK3 $\beta$ mRNA expression and 3-year survival rate in patients after operation. In the Experimental group, MRP1 mRNA was highly expressed in 68 patients and expression was 


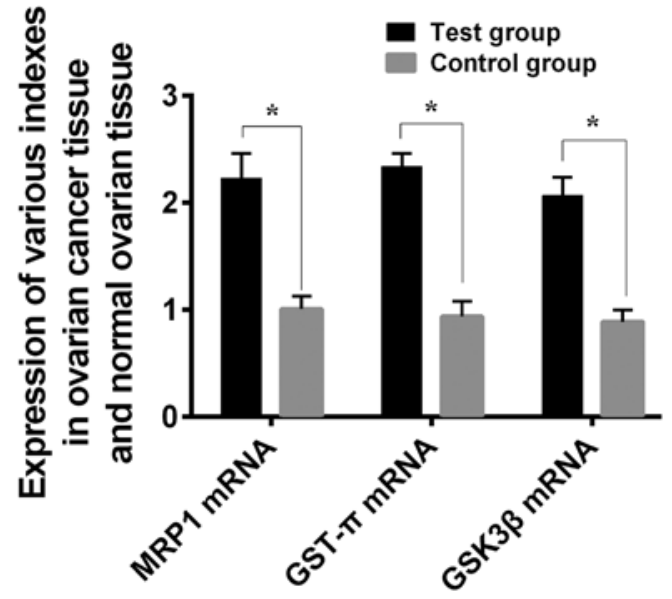

Figure 1. Comparison of MRP1, GST- $\pi$, and GSK $3 \beta$ mRNA expression levels in ovarian tissues between the Experimental group and the Control group. The results of RT-PCR revealed that the expression levels of MRP1, GST- $\pi$ and GSK $3 \beta$ mRNA in the ovarian cancer tissues of the Experimental group were statistically much higher than those in the ovarian tissues of the Control group ( $\mathrm{P}<0.05)$. MRP1, multidrug resistance-associated protein 1; GST- $\pi$, glutathione S-transferase $\pi$; GSK $3 \beta$, glycogen synthase kinase- $3 \beta$.

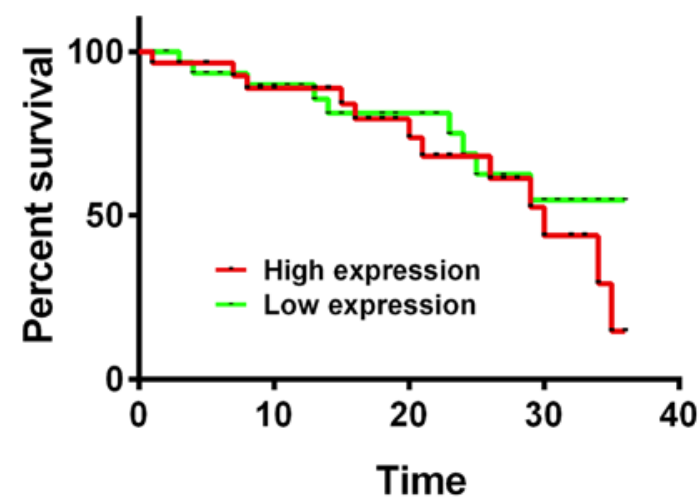

Figure 2. Association between MRP1 mRNA expression and 3-year survival rate after surgery. Kaplan-Meier survival analysis and log rank test revealed that the 3-year survival rate of patients with high MRP1 mRNA expression was significantly lower than that of patients with low expression, and the difference was statistically significant $(\mathrm{P}<0.05)$. MRP1, multidrug resistance-associated protein 1.

low in 53 patients; GST- $\pi \mathrm{c}$ mRNA was highly expressed in 65 patients and expression was low in 56 patients; GSK3 $\beta$ mRNA was highly expressed in 69 patients and expression was low in 52 patients. The 3 -year survival rates of patients with high expression of MRP1 mRNA, GST- $\pi$ mRNA, and GSK $3 \beta$ mRNA were $33.82,36.92$ and $34.78 \%$, respectively, much lower than the 3-year survival rates of patients with low expression of MRP1 mRNA, GST- $\pi$ mRNA, and GSK3 $\beta$ mRNA $(52.83,53.57$, and $51.92 \%$, respectively), and the difference was statistically significant $(\mathrm{P}<0.05)$ (Figs. 2-4).

\section{Discussion}

Ovarian cancer, a common gynecological malignant tumor, with few obvious symptoms in its early stage, is often not correctly diagnosed until reaching the middle and advanced stages when surgical resection is not practicable (15). Therefore, chemotherapy has become the main treatment for

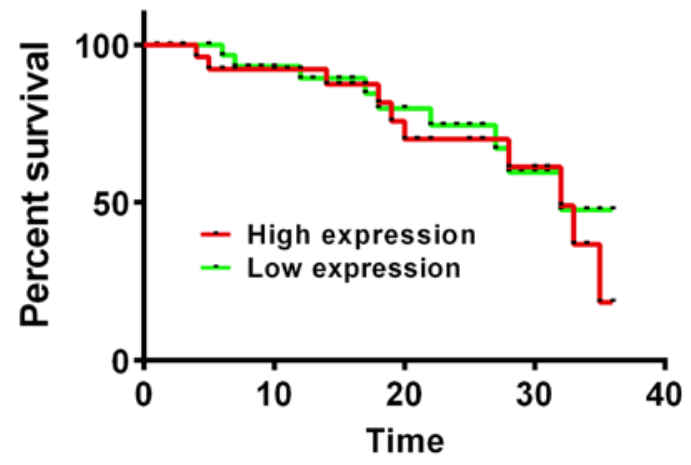

Figure 3. The relationship between GST- $\pi$ mRNA expression and 3-year survival rate after surgery. Kaplan-Meier survival analysis and log rank test presented a statistically lower 3-year survival rate in patients with high GST- $\pi$ mRNA expression than patients with low expression $(\mathrm{P}<0.05)$. GST $-\pi$, glutathione S-transferase $\pi$.

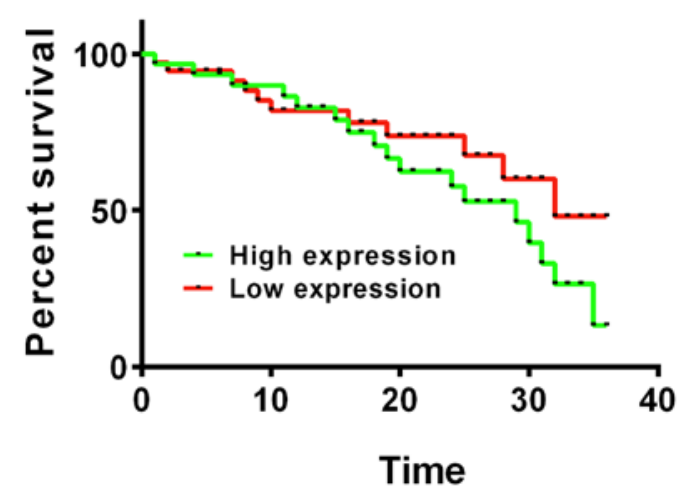

Figure 4. The relationship between GSK3 $\beta$ mRNA expression and 3-year survival rate after surgery. Kaplan-Meier survival analysis and log rank test showed that patients with high expression of GSK $3 \beta$ mRNA had a lower 3 -year survival rate than patients with low expression, and the difference was statistically significant $(\mathrm{P}<0.05)$. GSK $3 \beta$, glycogen synthase kinase- $3 \beta$.

patients with advanced ovarian cancer, but the accompanied drug resistance can have a serious impact on the treatment efficacy and the survival of patients (16). Moreover, drug resistance in intravenous chemotherapy can increase the recurrence rate of ovarian cancer and lead to an exacerbation of the prognosis of patients (17). MRPI, a drug resistance gene, has a strengthened ability to transport a negatively charged drug when highly expressed so as to reduce the drug concentration (18). GST- $\pi$ can activate ATP-dependent transport enzymes on cancer cell membranes to promote excretion of chemotherapy drugs from cancer cells to reduce drug concentration (19). Many studies have indicated that the subsequent drug resistance of residue ser-9 after its activation makes a great contribution to GSK-3 $\beta$ 's function of cancer suppression in the occurrence and development of various tumors (20). The aforementioned three factors are currently the most studied drug-related factors in clinical research. Considering the serious impact of chemotherapy resistance of ovarian cancer on patients, an effective prediction of the chemotherapy sensitivity of patients is essential.

In this study, the expression of MRP1 mRNA, GST- $\pi$ mRNA, and GSK $3 \beta$ mRNA by RT-PCR was compared between ovarian cancer tissues and normal ovarian tissues and their relationship in ovarian cancer with clinical pathological 
features and drug resistance of patients was analyzed. According to the experiment results, the expression of MRP1 mRNA was much higher in ovarian cancer tissues and in patients in the Chemotherapy-sensitive group, compared with its expression in normal ovarian tissues and in patients in the Chemotherapy-resistant group. Associated with pathological stage and pathological differentiation instead of age and pathological type, high MRP1 mRNA expression indicated a much shorter 3-year survival time than low MRP1 mRNA expression, suggesting a possible involvement of MRP1 in the chemotherapy resistance of ovarian cancer. Previous findings have shown that the expression of MRP1 in patients with advanced ovarian cancer is significantly higher than that in patients with early ovarian cancer, which is consistent with the conclusion of this study (21). Despite the lack of detailed study on the resistance mechanism of MRP1, some studies believed that MRP1's function of deconcentrating intracellular drugs is from its combination with glutathione (22). Similar to MRP1 mRNA, GST- $\pi$ mRNA and GSK $3 \beta$ mRNA were also more highly expressed in ovarian cancer tissues and in Chemotherapy-resistant group than in normal ovarian tissues and in Chemotherapy-sensitive group, and patients with high expression of GST- $\pi$ mRNA and GSK $3 \beta$ mRNA had a much shorter 3-year survival time than patients with low GST- $\pi$ mRNA and GSK $3 \beta$ mRNA expression. Such results suggest that both GST- $\pi$ and GSK3 $\beta$ may be involved in the chemotherapy resistance and prognosis of ovarian cancer. Previous findings identified that GST- $\pi$, with high expression in ovarian cancer tissues, together with MRP that has a strong positive expression in ovarian cancer, can be used as predictors of tumor recurrence, drug resistance, and poor prognosis $(23,24)$. When exploring the relationship between GST- $\pi$ expression and chemotherapy in patients with ovarian cancer it was found that patients with GST- $\pi$-positive expression were less sensitive to chemotherapy than patients with GST- $\pi$-negative expression, which is similar to the findings of this study (25). A study concluded that the sustained inhibition on GSK3 $\beta$ activity, a potential hallmark of tumorigenesis, may reduce apoptosis induced by chemotherapeutic drugs, suggesting that suppression on GSK $3 \beta$ activity may be one of the mechanisms of chemical resistance in tumor cells (26). In a previous study, the conclusion on the mechanism of the tumorigenesis of ovarian cancer after inhibiting the activity of GSK-3 $\beta$ in breast cancer cell lines drawn was that the inhibition of GSK-3 $\beta$ activity leads to abnormal activation of Wnt pathway, which causes the accumulation of $\beta$-catenin in the nucleus of tumor cells and the accelerated proliferation of tumor cells, thereby promoting the occurrence of breast tumors (27).

In summary, this study explored several important factors involved in drug resistance: MRP1, GST- $\pi$, and GSK3 $\beta$ which are highly expressed in ovarian cancer and thus involved with the drug resistance and prognosis and capable of performing as a target factor for predicting chemotherapy resistance and prognosis of ovarian cancer and supporting the prediction of clinical chemotherapy efficacy. However, the specific mechanisms of MRP1, GST- $\pi$, and GSK3 $\beta$ in chemotherapy resistance in patients with ovarian cancer have not been explored in detail. Thus continued research efforts should be made to identify the underlying mechanism.

\section{Acknowledgements}

Not applicable.

\section{Funding}

No funding was received.

\section{Availability of data and materials}

The datasets used and/or analyzed during the present study are available from the corresponding author on reasonable request.

\section{Authors' contributions}

XT wrote the manuscript. XT and JZ analyzed and interpreted the patient general data. YZ and PM performed PCR. XW was responsible for the analysis of the observation indicators. All authors read and approved the final manuscript.

\section{Ethics approval and consent to participate}

The study was approved by the Ethics Committee of Liaoning Cancer Hospital and Institute, Cancer Hospital of China Medical University (Shenyang, China). Patients who participated in this research had complete clinical data. Signed informed consents were obtained from the patients or the guardians.

\section{Patient consent for publication}

Not applicable.

\section{Competing interests}

The authors declare that they have no competing interests.

\section{References}

1. Jacobs IJ, Menon U, Ryan A, Gentry-Maharaj A, Burnell M, Kalsi JK, Amso NN, Apostolidou S, Benjamin E, Cruickshank D, et al: Ovarian cancer screening and mortality in the UK Collaborative Trial of Ovarian Cancer Screening (UKCTOCS): A randomised controlled trial. Lancet 387: 945-956, 2016.

2. Duran GE, Wang YC, Moisan F, Francisco EB and Sikic BI: Decreased levels of baseline and drug-induced tubulin polymerisation are hallmarks of resistance to taxanes in ovarian cancer cells and are associated with epithelial-to-mesenchymal transition. Br J Cancer 116: 1318-1328, 2017.

3. Chen FQ, Zhang JM, Fang XF, Yu H, Liu YL, Li H, Wang YT and Chen MW: Reversal of paclitaxel resistance in human ovarian cancer cells with redox-responsive micelles consisting of $\alpha$-tocopheryl succinate-based polyphosphoester copolymers. Acta Pharmacol Sin 38: 859-873, 2017.

4. Wu W, Fan L, Bao Z, Zhang Y, Peng Y, Shao M, Xiang Y, Zhang X, Wang Q and Tao L: The cytoplasmic translocation of Cx32 mediates cisplatin resistance in ovarian cancer cells. Biochem Biophys Res Commun 487: 292-299, 2017.

5. Huang ZL, Cao X, Luo RZ, Chen YF, Zhu LC and Wen Z: Analysis of ERCC1, BRCA1, RRM1 and TUBB3 as predictors of prognosis in patients with non-small cell lung cancer who received cisplatin-based adjuvant chemotherapy: A prospective study. Oncol Lett 11: 299-305, 2016.

6. Stott W, Campbell S, Franchini A, Blyuss O, Zaikin A Ryan A, Jones C, Gentry-Maharaj A, Fletcher G, Kalsi J, et al: Sonographers' self-reported visualization of normal postmenopausal ovaries on transvaginal ultrasound is not reliable: Results of expert review of archived images from UKCTOCS. Ultrasound Obstet Gynecol 51: 401-408, 2018. 
7. Thomas DS, Fourkala EO, Apostolidou S, Gunu R, Ryan A Jacobs I, Menon U, Alderton W, Gentry-Maharaj A and Timms JF: Evaluation of serum CEA, CYFRA21-1 and CA125 for the early detection of colorectal cancer using longitudinal preclinical samples. Br J Cancer 113: 268-274, 2015.

8. Niiro E, Morioka S, Iwai K, Yamada Y, Ogawa K, Kawahara N and Kobayashi H: Potential signaling pathways as therapeutic targets for overcoming chemoresistance in mucinous ovarian cancer. Biomed Rep 8: 215-223, 2018.

9. Abdallah EA, Fanelli MF, Souza E Silva V, Machado Netto MC, Gasparini Junior JL, Araújo DV, Ocea LM, Buim ME, Tariki MS, Alves VS, et al: MRP1 expression in CTCs confers resistance to irinotecan-based chemotherapy in metastatic colorectal cancer. Int J Cancer 139: 890-898, 2016.

10. Yang X, Leslie G, Gentry-Maharaj A, Ryan A, Intermaggio M, Lee A, Kalsi JK, Tyrer J, Gaba F, Manchanda R, et al: Evaluation of polygenic risk scores for ovarian cancer risk prediction in a prospective cohort study. J Med Genet 55: 546-554, 2018.

11. Jenkins V, Fallowfield L, Langridge C, Barrett J, Ryan A, Jacobs I, Kilkerr J, Menon U and Farewell V: Psychosocial factors associated with withdrawal from the United Kingdom Collaborative Trial of Ovarian Cancer Screening after 1 episode of repeat screening. Int J Gynecol Cancer 25: 1519-1525, 2015.

12. Basak P, Sadhukhan P, Sarkar P and Sil PC: Perspectives of the Nrf-2 signaling pathway in cancer progression and therapy. Toxicol Rep 4: 306-318, 2017.

13. Livak KJ and Schmittgen TD: Analysis of relative gene expression data using real-time quantitative PCR and the 2(-Delta Delta C(T)) method. Methods 25: 402-408, 2001.

14. Yao HP: Diagnosis and treatment of recurrent ovarian cancer. Zhonghua Fu Chan Ke Za Zhi 38: 659-660, 2003 (In Chinese).

15. Gizzo S, Noventa M, Quaranta M, Vitagliano A, Saccardi C, Litta P and Antona D: A novel hysteroscopic approach for ovarian cancer screening/early diagnosis. Oncol Lett 13: 549-553, 2017.

16. Ataie-Kachoie P, Pillai K, Badar S, Akhter J and Morris DL: Monepantel considerably enhances the therapeutic potentials of PEGylated liposomal doxorubicin and gemcitabine in ovarian cancer: In vitro and in vivo studies. Am J Cancer Res 8 : 2064-2075, 2018.

17. Qin M, Jin Y, Ma L, Zhang YY and Pan LY: The role of neoadjuvant chemotherapy followed by interval debulking surgery in advanced ovarian cancer: A systematic review and meta-analysis of randomized controlled trials and observational studies. Oncotarget 9: 8614-8628, 2017.

18. Senft D, Qi J and Ronai ZA: Ubiquitin ligases in oncogenic transformation and cancer therapy. Nat Rev Cancer 18: 69-88, 2018.
19. Zhang KG, Qin CY, Wang HQ, Wang JX and Wang QM: The effect of TRAIL on the expression of multidrug resistant genes MDR1, LRP and GST- $\pi$ in drug-resistant gastric cancer cell SGC7901/VCR. Hepatogastroenterology 59: 2672-2676, 2012.

20. Menon U, McGuire AJ, Raikou M, Ryan A, Davies SK, Burnell M, Gentry-Maharaj A, Kalsi JK, Singh N, Amso NN, et al: The cost-effectiveness of screening for ovarian cancer: Results from the UK Collaborative Trial of Ovarian Cancer Screening (UKCTOCS). Br J Cancer 117: 619-627, 2017.

21. Sedláková I, Laco J, Tošner J, Spaček J and Cermáková E Drug resistance proteins LRP, Pgp, MRP1, MRP3 and MRP5 in ovarian cancer patients. Ceska Gynekol 78: 545-553, 2013 (In Czech).

22. Ji Q and Qiu L: Mechanism study of PEGylated polyester and $\beta$-cyclodextrin integrated micelles on drug resistance reversal in MRP1-overexpressed HL60/ADR cells. Colloids Surf B Biointerfaces 144: 203-213, 2016.

23. Fallowfield L, Solis-Trapala I, Menon U, Langridge C, May S, Jacobs I and Jenkins V: The effect of ovarian cancer screening on sexual activity and functioning: Results from the UK collaborative trial of ovarian cancer screening RCT. Br J Cancer 116: 1111-1117, 2017.

24. Cao DY, Shen K, Yang JX and Guan J: The expression of MRP GST-pi, Topo IIalpha and COX-2 in epithelial ovarian cancer and its relationship to drug resistance and prognosis. Zhonghua Yi Xue Za Zhi 87: 1738-1741, 2007 (In Chinese)

25. Russell MR, Graham C, D'Amato A, Gentry-Maharaj A, Ryan A, Kalsi JK, Ainley C, Whetton AD, Menon U, Jacobs I, et al: A combined biomarker panel shows improved sensitivity for the early detection of ovarian cancer allowing the identification of the most aggressive type II tumours. Br J Cancer 117: 666-674, 2017.

26. Beurel E, Kornprobst M, Blivet-Van Eggelpoël MJ, Cadoret A, Capeau J and Desbois-Mouthon C: GSK-3beta reactivation with LY294002 sensitizes hepatoma cells to chemotherapy-induced apoptosis. Int J Oncol 27: 215-222, 2005.

27. Farago M, Dominguez I, Landesman-Bollag E, Xu X, Rosner A, Cardiff RD and Seldin DC: Kinase-inactive glycogen synthase kinase 3 beta promotes Wnt signaling and mammary tumorigenesis. Cancer Res 65: 5792-5801, 2005.

This work is licensed under a Creative Commons

Attribution-NonCommercial-NoDerivatives 4.0 International (CC BY-NC-ND 4.0) License. 